\title{
Isolation of Protease Producing Strains and Evaluation of Protease Assay from Fecal Water and Curd Samples
}

\section{Eswari Beeram*}

Assistant Professor, Department of Chemical Sciences, Sree Vidyanikethan Degree College, AP, India

*Corresponding Author: Eswari Beeram, Assistant Professor, Department of Chemical Sciences, Sree Vidyanikethan Degree College, AP, India.
Received: July 31, 2021

Published: August 12, 2021

(C) All rights are reserved by Eswari Beeram.

\begin{abstract}
E. coli and yeast strain S. cerevisiae are the well known microbiota in the microbial world and can be easily isolated from the contaminated water bodies. So, we have chosen these two organisms because of their abundant availability, ease of plating and culturing on media. Proteases are most important in detergent industry and it is easy to isolate protease in large quantities from $E$. coli and Yeast strain $S$. cerevisiae and can recover the protease with low cost downstream processing methods. This article mainly focuses on the preliminary results about the secretion of protease in to the medium by fungi $S$. cerevisiae without requirement for autolysis and found to be cost effective. The protease can be recovered easily by simple pelleting of cells at $4000 \mathrm{rpm}$ for $15 \mathrm{~min}$.
\end{abstract}

Keywords: Gram Staining; S. cerevisiae; Methylene blue; Autolysis; Protease; Autolysis; Ammonium Hydroxide; Toulene

\section{Background}

Proteases are now considered as enzymes with major market potential that can be used in detergents, various meat industries etc. [1-4] and production of the proteases using microorganisms is one of the key applications in the industrial biotechnology. Proteases are considered as peptidyl peptide hydrolases that hydrolyse the peptide bond in proteins [5]. Microbes like E. coli and S. cerevisiae can be easily isolated from the contaminated water and curd samples. Proteases accounts for the third largest group of enzymes in the world market sale and accounts for about $60 \%$ of total industrially produced enzymes [6].

Acid proteases are the group of enzymes mainly produced by the fungi [7] and where as neutral proteases are mainly by plants. Alkaline phosphatases act at basic $\mathrm{pH}$ and these are major proteases used in detergent and food industries worldwide [1-4,8]. Bac- terial proteases are mainly preferred due to their ease with genetic manipulations with the help of recombinant technology produced majorly from Bacillus strain.

Applications of proteases in tanning industries and one of the protease Keratinase from Bacillus strain is mainly involved in degradation of nondegradable waste in to biodegradable substances $[9,10]$. Detergent industries use alkaline proteases the serine proteases optimally active at alkaline $\mathrm{pH}$ between 9 - 11. Different mushrooms containing alkaline proteases have reported $[11,12]$ so far, uses a simple method without any downstream processing in the methodology is one of the major advances in microbiology field.

\section{Methodology}

Isolation of $E$. coli from contaminated water samples

$1 \mathrm{ml}$ of sewage water and fecal contaminated water was collected from the near village sewage rangampet and was serially 
diluted using $1 \mathrm{ml}$ pipette in to sterile autoclaved test tubes containing $9 \mathrm{ml}$ of distilled water in each tube. The culturing of $E$. coli and $S$. cerevisiae was done by inoculating $0.1 \mathrm{ml}$ of sample on to solidified nutrient agar plate by spread plate method. Dilutions of $10^{-8}$ and $10^{-9}$ was used to plate the sample on Macconkey agar and incubated at $34^{\circ} \mathrm{C}$ for $24 \mathrm{hrs}$. But confluent colonies was observed on the next day.

\section{Isolation of yeast from curd sample}

$1 \mathrm{~g}$ of curd was serially diluted was mentioned above and $0.1 \mathrm{ml}$ of sample was plated on to the solidified potato dextrose agar plates and incubated at $34^{\circ} \mathrm{C}$ for $48 \mathrm{hrs}$ to observe the colony growth .

\section{Methylene blue staining [17]}

Isolated fungal samples are confirmed as yeast by using methylene blue staining. Equal amounts of yeast and methylene blue stain was taken, smeared on the glass slide and allowed to dry. The slide was observed under low power objective and the images are captured.

\section{Gram staining}

Gram staining was performed by standard protocol designed by Christian grams.

\section{Autolysis of yeast and E. coli [18]}

E. coli and yeast isolated was inoculated in to broth cultures and about $35 \mathrm{ml}$ of culture is separated in laminar air flow under sterile conditions and $10 \mathrm{ml}$ of toluene and $10 \mathrm{ml}$ of $10 \%$ Ammonium hydroxide is added to the cultures and incubated at $34^{\circ} \mathrm{C}$ for $72 \mathrm{hrs}$ and the autolysed culture is pelleted and used for the plating. Cultures which are not used for autolysis is also subjected to pelleting and the supernatant is used for plating. Supernatant samples of both autolysed and unautolysed samples are used for protease assay to know the localization of protease in yeast and E. coli.

\section{Protease assay}

$1 \mathrm{mg} / 1 \mathrm{ml}$ of BSA and ovalbumin samples are prepared and used for the determination of protease assay. $5 \mathrm{ml}$ of the solution is separated in each test tube and supernatant samples each of 150 $\mu \mathrm{l}$ of $S$. cerevisiae e is added into different test tubes containing ovalbumin, BSA and mixture of ovalbumin and BSA, and subjected to incubation for $15 \mathrm{~min}$ at lower degree temperatures. In case of $E$. coli only $30 \mu \mathrm{l}$ of supernatant is taken. After time period the values are recorded in UV- Visible spectrophotometry at $280 \mathrm{~nm}$.
Results

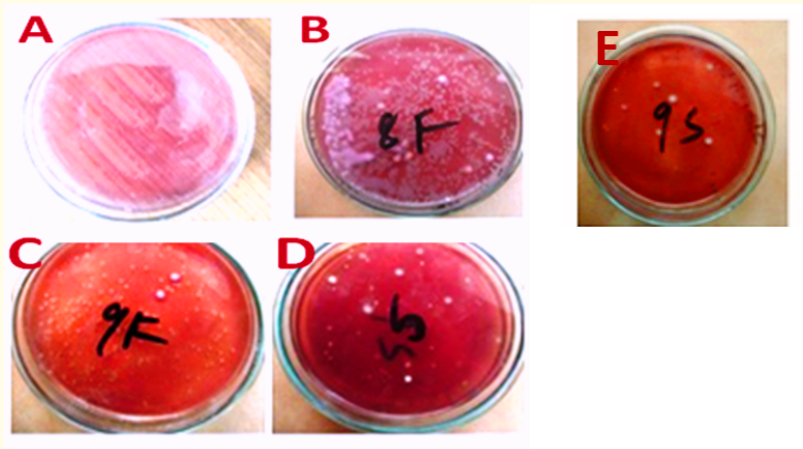

Figure 1: Isolation of E. coli from sewage water and fecal contaminated water and isolation of $S$. cerevisiae from curd sample. (A) Agar plate with control and (B) and (C) plates is the isolated E. coli from $10^{-8}$ and $10^{-9}$ dilutions of fecal contaminated water where as (D) and (E) plates is the isolated E. coli from $10^{-8}$ and $10^{-9}$ dilutions of sewage water.
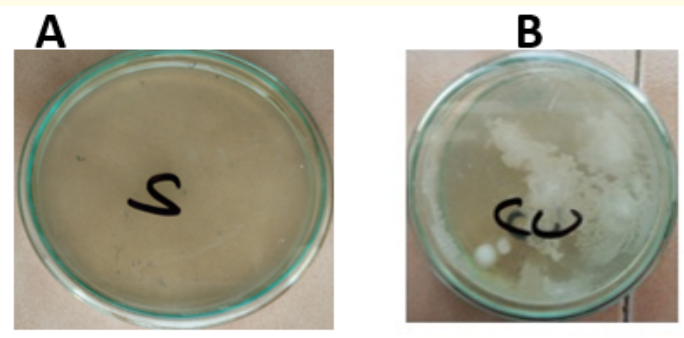

Figure 2: Isolation of S. cerevisiae from curd sample. (A) Agar plate of control (B) Agar plate containing S. cerevisiae isolated from curd sample.

E. coli cells was isolated from the sewage water and fecal contaminated water by serial dilution and spread plate methods using $10^{-8}$ and $10^{-9}$ dilutions of samples on Macconkey agar. After plating the confluent growth was observed on $2^{\text {nd }}$ day. The isolated samples were identified by gram staining as gram negative rods and used for culturing of E. coli under pure conditions. Similarly, yeast was isolated from curd sample by using Potato dextrose agar 
and confirmed using methylene blue staining after 2 days of inoculation.

A

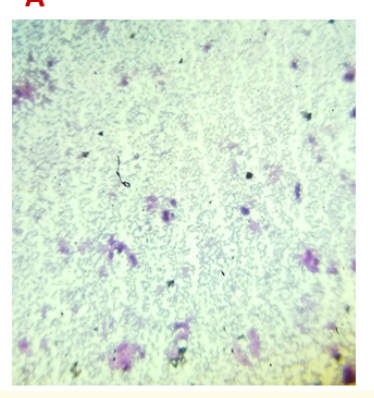

B

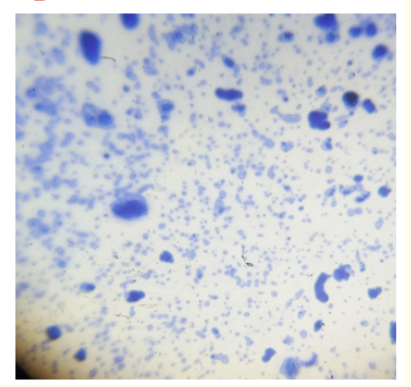

Figure 3: Figure (A) is the confirmation of E. coli by Gram's staining. Figure (B) is the confirmation of S. cerevisiae by methylene blue staining.
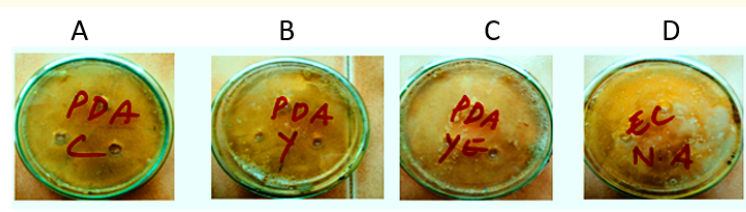

E

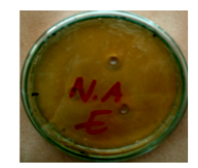

Figure 4: Cultivation of bacteria in Nutrient agar and Potato dextrose agar after autolysis of bacteria and yeast. Figure $4 \mathrm{~A}$ is control, figure (4B) S. cerevisiae sample applied on agar plate after autolysis, (c) is the supernatant of $S$. cerevisiae applied on agar plate after pelleting the cells at 4000rpm for 15 without any autolysis cultured in broth'. Figure 4D is the supernatant of pelleted E. coli cells with out any autolysis and figure 4 E plate is the autolysed E. coli sample. The white colour froth in the $2^{\text {nd }}$ plate is due to BSA added to the plate in order to check the protease activity.

From the table 1 viability of bacteria can be easily studied as autolysis releases the cellular contents resulting in increase of the OD and from figure 4 autolysed samples doesn't shown growth on
Nutrient agar plats and as well as Potato dextrose agar plates. From table two secrete the protease in to cultures instead of killing them. From the table 2 it is clear that bacteria secrete acid proteases which results in inactivation of protease at alkaline $\mathrm{pH}$ due to ammonium hydroxide. S. cerevisiae secretes protease in to the culture where as E. coli doesn't secrete in to medium and needs to be autolysed before isolation of protease, as we have used same pelleting procedure for yeast and E. coli.

\begin{tabular}{|l|c|c|}
\hline $\begin{array}{l}\text { S. } \\
\text { No }\end{array}$ & & OD at $\mathbf{6 0 0 n m}$ \\
\hline & E. coli with out autolysis & 1.00 \\
\hline & E. coli culture after autolysis & 1.67 \\
\hline & Yeast culture with out autolysis & 0.11 \\
\hline & Yeast culture after autolysis & 0.26 \\
\hline
\end{tabular}

Table 1: Measurement of viability of $E$. coli and yeast by colorimeter at OD $600 \mathrm{~nm}$.

From the figure 4 and the table 1 it is clearly identified as autolysis is complete as the bacteria and yeast are unable to form colonies on inoculation with autolysed sample. The increase in OD in the autolysed samples is due to the cellular contents released in to the media.

\begin{tabular}{|l|c|c|c|}
\hline & $\begin{array}{c}\text { OD at 280nm } \\
\text { (BSA) }\end{array}$ & $\begin{array}{c}\text { OD at 280nm } \\
\text { (Ovalbumin) }\end{array}$ & $\begin{array}{c}\text { OD at 280nm } \\
\text { (Ovalbumin } \\
\text { +BSA) }\end{array}$ \\
\hline Control & 0.00 & 0.00 & 0.00 \\
\hline $\begin{array}{l}\text { Standard with- } \\
\text { out protease }\end{array}$ & 0.622 & 0.482 & 0.590 \\
\hline Yeast culture & 0.67 & 0.396 & 0.612 \\
\hline $\begin{array}{l}\text { Autolysed yeast } \\
\text { sample }\end{array}$ & 0.739 & 0.355 & 0.585 \\
\hline $\begin{array}{l}\text { E. coli culture } \\
\text { Autolysed E. coli } \\
\text { sample }\end{array}$ & 0.659 & 0.569 & 0.692 \\
\hline
\end{tabular}

Table 2: Measurement of protease activity from cultured cells and autolysed samples by using Bovine serum albumin, Ovalbumin and mixture of BSA +Ovalbumin.

From the table 2 we can reuse the same $S$. cerevisiae for the production of protease from strain without autolysing them and 
maintaining sterile conditions during isolation of protease from $S$. cerevisiae which proves to be cost effective. The protease of yeast was highly effective against ovalbumin compared to Bovine serum albumin. E. coli protease is less effective against ovalbumin compared to $S$. cerevisiae protease and Protease assay was carried out at low temperatures and the activity was recorded at $280 \mathrm{~nm}$ in U.V Visible spectrophotometry (shimadzu double beam spectrophotometer).

\begin{tabular}{|l|c|c|c|}
\hline S.no & & E. coli (CFU) & Yeast \\
\hline 1. & Control & 0 & 0 \\
\hline 2. & $10^{-8}$ fecal sample & $500-600$ & $\begin{array}{c}\text { Not seen as } \\
\text { colonies }\end{array}$ \\
\hline 3. & $10^{-9}$ fecal sample & 95 & $\begin{array}{c}\text { Not seen as } \\
\text { colonies }\end{array}$ \\
\hline 4. & $10^{-8}$ sewage sample & 35 & $\begin{array}{c}\text { Not seen as } \\
\text { colonies }\end{array}$ \\
\hline 5. & $10^{-9}$ sewage sample & 9 & $\begin{array}{c}\text { Not seen as } \\
\text { colonies }\end{array}$ \\
\hline
\end{tabular}

Table 3

\section{Discussion}

According to Kanatani., et al. the protease present in E. coli is Protease II with molwt 81858D deduced from the nucleotide sequencing. The active ser residue of the protease was ser-532 and doesn't showed homology with other proteases found in E. coli except with the ser active region [13]. From Visweshwar Regode., et al. for the conversion of cry toxin (B. thurengeinsis) in to active form requires protease and it was found to be inhibited by PMSF followed by EDTA and effective against pathogens Helicovepa armigera and E. coli [14].

From Gilbert., et al. (1988) one of the protease isolated from Streptococcus sangius showed the IgA1 protease activity to the IgA of humans and shown to cleave the peptide bond in the hinge region of $\operatorname{IgA}$, but the protease lacks sequence similarity with the $E$. coli proteases [15].

According to D. Ribitsch., et al. (2012) some extracellular proteases have been isolated from Stenotrophomonas maltophilia and expressed in E. coli but truncation of C- terminal domain has restored activity only with StmPr1 and failed in case of StmPr3 [16]. So many scientists have isolated the proteases from different strains and expressed in E. coli but isolation of proteases that have direct applications in biotechnology requires attention even now.

\section{Conclusion}

From the study I can conclude that using S. cerevisiae for protease production can reduce the downstream processing in detergent industry and also proven to be cost effective.

\section{Bibliography}

1. AA Kembhavi., et al. "Salt-tolerant and thermostable alkaline protease From Bacillus subtilis NCIM No. 64". Applied Biochemistry and Biotechnology 38 (1993): 83-92.

2. Gessesse A and Gashe BA. "Production of alkaline protease by an alkalophilic bacteria isolated from an alkaline soda lake". Biotechnology Letters 19 (1997): 479-481.

3. CG Kumar and H Takagi. "Microbial alkaline proteases: from a bioindustrial viewpoint". Biotechnology Advances 17 (1999): 561-594.

4. PL Manachini and MG Fortina. "Production in sea-water of thermostable alkaline proteases by a halotolerant strain of Bacillus licheniformis". Biotechnology Letters 20 (1998): 565568.

5. Pradeep Palsaniya., et al. "Optimization of alkaline protease production from Bacteria isolated from soil". Journal of Microbiology and Biotechnology Research's 2.6 (2010): 858-865.

6. Nurullah Akcan and Fikret Uyar. "Production of extracellular alkaline protease from Bacillus subtilis RSKK96 with solid state fermentation". EuAsian Journal of Biosciences 5 (2011): 64-72.

7. Odu N N and Akujobi C O. "Protease Production Capabilities of Micrococcus Luteus and Bacillus pecies isolated from Abattoir Environment". Journal of Microbiology Research 2.5 (2012): 127-132.

8. Sneath HAP and Halt G J. eds. Bergeys Manual of Systematic Bacteriology 2 (1986).

9. Cavello I A., et al. "Plant growth promotion activity of keratinolytic fungi growing on a recalcitrant waste known as "Hair Waste”. Biotechnology Research International (2015): 952921. 
10. Gupta R and Ramnani P. "Microbial keratinases and their prospective applications: an overview". Applied Microbiology and Biotechnology 70 (2006): 21.

11. Hossain MM., et al. "Plant growth-promoting fungi (PGPF): phytostimulation and induced systemic resistance". in PlantMicrobe Interactions in Agro-Ecological Perspectives, eds D. P. Singh, H. B. Singh, and R. Prabha (Singapore: Springer) (2017): 135-191.

12. Adetunji C $\mathrm{O}$ and Adejumo I O. "Efficacy of crude and immobilized enzymes from Bacillus licheniformis for production of biodegraded feather meal and their assessment on chickens". Environmental Technology and Innovation 11 (2018): 116-124.

13. Akio Kanatani., et al. "Protease II from Escherichia coli: Sequencing and Expression of the Enzyme Gene and Characterization of the Expressed Enzyme". Journal of Biochemistry 110 (1991): 315-320.

14. Regode Visweshwar, et al. "Isolation and Characterization of Gut Bacterial Proteases Involved in Inducing Pathogenicity of Bacillus thuringiensis Toxin in Cotton Bollworm, Helicoverpa armigera". Frontiers in Microbiology 7 (2016): 1567.

15. Joanne V Gilbert., et al. "Cloning of the Gene Encoding Streptococcal Immunoglobulin A Protease and Its Expression in Escherichia coli". Infection and Immunity 56.8 (1988): 1961-1966.

16. D Ribitsch., et al. "Extracellular serine proteases from Stenotrophomonas maltophilia: Screening, isolation and heterologous expression in E. coli". Journal of Biotechnology 157.1 (2012): 140-147.

17. Magdalena Kwolek-Mirek and Renata Zadrag-Tecza. "Comparison of methods used for assessing the viability and vitality of yeast cells". FEMS Yeast Research 14.7 (2014): 1068-1079.

18. Protein Purification - Extraction and Clarification - Preparation of cell lysates from yeast - EMBL.

\section{Volume 4 Issue 9 September 2021}

(C) All rights are reserved by Eswari Beeram. 